Article

\title{
Syntheses and Characterization of Two Dicyanamide Compounds Containing Monovalent Cations: $\mathrm{Hg}_{2}\left[\mathrm{~N}(\mathrm{CN})_{2}\right]_{2}$ and $\mathrm{Tl}\left[\mathrm{N}(\mathrm{CN})_{2}\right]$
}

\author{
Markus Mann ${ }^{1}$, Olaf Reckeweg ${ }^{1}{ }^{\circledR}$, Nils Nöthling ${ }^{2}{ }^{(0}$, Richard Goddard ${ }^{2}$ and \\ Richard Dronskowski ${ }^{1, *(D)}$ \\ 1 Chair of Solid-State and Quantum Chemistry, Institute of Inorganic Chemistry, RWTH Aachen University, \\ 52056 Aachen, Germany; markus.mann@ac.rwth-aachen.de (M.M.); olaf.reykjavik@gmx.de (O.R.) \\ 2 Max-Planck-Institut für Kohlenforschung, 45470 Mülheim an der Ruhr, Germany; \\ noethling@mpi-muelheim.mpg.de (N.N.); goddard@mpi-muelheim.mpg.de (R.G.) \\ * Correspondence: drons@HAL9000.ac.rwth-aachen.de; Tel.: +49-241-809-3642; Fax: +49-241-809-2642
}

Received: 6 December 2018; Accepted: 13 December 2018; Published: 18 December 2018

check for updates

\begin{abstract}
Crystals of $\mathrm{Hg}_{2}\left[\mathrm{~N}(\mathrm{CN})_{2}\right]_{2}$ were grown by a slow diffusion-reaction between aqueous $\mathrm{Hg}_{2}\left(\mathrm{NO}_{3}\right)_{2} \cdot 2 \mathrm{H}_{2} \mathrm{O}$ and $\mathrm{Na}\left[\mathrm{N}(\mathrm{CN})_{2}\right] . \mathrm{Hg}_{2}\left[\mathrm{~N}(\mathrm{CN})_{2}\right]_{2}$ adopts the triclinic space group $P \overline{1}$ (no. 2) with $a=3.7089(5), b=6.4098(6), c=8.150(6) \AA, \alpha=81.575(6)^{\circ}, \beta=80.379(7)^{\circ}, \gamma=80.195(7)^{\circ}$, and $Z=1$. Crystals of $\operatorname{Tl}\left[\mathrm{N}(\mathrm{CN})_{2}\right]$ were obtained from the reaction of $\mathrm{TlBr}$ with $\mathrm{Ag}\left[\mathrm{N}(\mathrm{CN})_{2}\right]$ in water. Single-crystal structure analyses evidence that $\mathrm{Tl}\left[\mathrm{N}(\mathrm{CN})_{2}\right]$ is isotypic to $\alpha-\mathrm{K}\left[\mathrm{N}(\mathrm{CN})_{2}\right]$ and adopts the orthorhombic space group Pbcm (no. 57) with $a=8.5770(17), b=6.4756(13), c=7.2306(14)$ $\AA$, and $Z=4$. Regarding volume chemistry, the dicyanamide anion occupies $\mathrm{ca} .44 \mathrm{~cm}^{3} \cdot \mathrm{mol}^{-1}$, and so it corresponds to a large pseudohalide. The IR spectra of both compounds exhibit vibrational modes that are characteristic of the dicyanamide anion.
\end{abstract}

Keywords: dicyanamide; mercury; thallium; crystal structure; volume chemistry; IR spectrum; metathesis

\section{Introduction}

Nitrogen-based solid-state materials have found extremely diverse applications, for example, as simple fertilizers, as high-performance steel coatings, as III-V optical semiconductors, and, quite recently, even as lithium- and sodium-ion battery materials. In particular, complex nitrogen containing compounds beyond the simple, yet fundamental nitrides, such as carbodiimides or guanidinates, are promising materials [1-3]. Similar to the latter in terms of chemical functionality, another interesting inorganic moiety is the boomerang-shaped dicyanamide anion $\left[\mathrm{N}(\mathrm{CN})_{2}\right]^{-}$, which is often dubbed as $[\mathrm{dca}]^{-}$. It is intriguing, since it possesses one doubly-coordinated and two singly-coordinated nitrogen atoms plus several electron lone pairs.

Generally speaking, the solubility of a metal dicyanamide in water is an important factor regarding the synthetic strategy of whatever binary or ternary phase is targeted. If the desired product is insoluble in water and can be filtered off after a metathesis reaction with $\mathrm{Na}[\mathrm{dca}]$, therefore this method can be used to grow crystals via a diffusion reaction. If the target compound is water soluble, however, it can be synthesized employing a metathesis reaction with $\mathrm{Ag}[\mathrm{dca}$. In this case, the driving force for the reaction is the subsequent formation of insoluble silver halides. After filtering to remove the silver halides, the product can then be crystallized by simply evaporating water. Binary dicyanamide compounds are known for ammonium [4], alkali metals [5-8] (except $\mathrm{Fr}$ ), alkaline-earth metals [9] (except Be and $\mathrm{Ra}$ ), transition metals (Cr-Zn, except Fe) [10-16], and rare-earth metals ( $\mathrm{La}, \mathrm{Ce}, \mathrm{Pr}, \mathrm{Nd}$, $\mathrm{Sm}, \mathrm{Eu}, \mathrm{Gd}, \mathrm{Tb}$ ) [17-19]. Ternary compounds, such as KCs[dca $]_{2}$ [20], LiK[dca $]_{2}$ [21], LiRb[dca $]_{2}$ [21], $\mathrm{NaRb}_{2}[\mathrm{dca}]_{3} \cdot \mathrm{H}_{2} \mathrm{O}[20], \mathrm{NaCs}_{2}[\mathrm{dca}]_{3}[22]$, and $\mathrm{LiCs}_{2}[\mathrm{dca}]_{3}[23]$ are also known. 
The synthesis of $\mathrm{Hg}_{2}[\mathrm{dca}]_{2}$ from $\mathrm{Hg}_{2}\left(\mathrm{NO}_{3}\right)_{2}$ with $\mathrm{Na}$ [dca] has been reported almost a century ago [24], but no structural characterization was performed. Another attempt to characterize $\mathrm{Hg}_{2}[\mathrm{dca}]_{2}$ by Kuhn and Mecke [25] in 1961 was based on IR data on a number of different dicyanamides. These measurements provided valid proof that the shape of the dicyanamide anion is kinked (or boomerang-shaped) instead of linear. Even though a working synthesis was known, no further investigations were made regarding the crystal structure of $\mathrm{Hg}_{2}[\mathrm{dca}]_{2}$. A further dicyanamide compound containing a monovalent cation with unknown crystal structure is $\mathrm{Tl}[\mathrm{dca}]$. Because of its high solubility in water, $\mathrm{Tl}[\mathrm{dca}]$ cannot be synthesized analogously to $\mathrm{Hg}_{2}[\mathrm{dca}]_{2}$. The use of $\mathrm{Ag}$ [dca] provides a convenient alternative route to the crystals of Tl[dca]. We here report the syntheses and single-crystal structure determinations of $\mathrm{Hg}_{2}\left[\mathrm{dca}_{2}\right.$ and $\mathrm{Tl}[\mathrm{dca}]$.

\section{Results and Discussion}

\subsection{Structural Description and Discussion}

$\mathrm{Hg}_{2}\left[\mathrm{~N}(\mathrm{CN})_{2}\right]_{2}$ adopts the triclinic space group $P \overline{1}$ (no. 2) with $a=3.7089(5), b=6.4098(6)$, $c=8.150(6) \AA, \alpha=81.575(6)^{\circ}, \beta=80.379(7)^{\circ}, \gamma=80.195(7)^{\circ}$, and $Z=1$. Similar to most $\mathrm{Hg}(\mathrm{I})$ compounds, crystalline $\mathrm{Hg}_{2}\left[\mathrm{~N}(\mathrm{CN})_{2}\right]_{2}$ contains $\mathrm{Hg}_{2}$ moieties with $d(\mathrm{Hg}-\mathrm{Hg})=2.518(3) \AA$. The structure can be compared to that of calomel, $\mathrm{Hg}_{2} \mathrm{Cl}_{2}$, where $d(\mathrm{Hg}-\mathrm{Hg})=2.53 \AA$ [26]. In $\mathrm{Hg}_{2}[\mathrm{dca}]_{2}$, every $\mathrm{Hg}_{2}$ dumbbell is bonded to two [dca] anions forming a quasi-molecular $\mathrm{Hg}_{2}[\mathrm{dca}]_{2}$ unit (Figure 1). A distorted octahedral coordination results for each $\mathrm{Hg}(\mathrm{I})$ due to four more coordinating nitrogen atoms. Therefore, every $\mathrm{Hg}(\mathrm{I})$ is surrounded by a total of five nitrogen belonging to five different [dca] anions, and also by the neighboring $\mathrm{Hg}(\mathrm{I})$ ion. Three of these dicyanamide anions coordinate the mercury ion with their terminal nitrogen atoms $(d(\mathrm{Hg}-\mathrm{N} 1)=2.166(10), d(\mathrm{Hg}-\mathrm{N} 3)=2.612(12)$, and $d(\mathrm{Hg}-\mathrm{N} 3)=2.834(10) \AA)$, whilst the others coordinate via their bridging nitrogen at a more distant $d(\mathrm{Hg}-\mathrm{N} 2)=3.084(9)$ and 3.412(22) $\AA$. Similar distorted coordination octahedra are also known for $\mathrm{Hg}_{2} \mathrm{Cl}_{2}$ [26] (Figure 2).

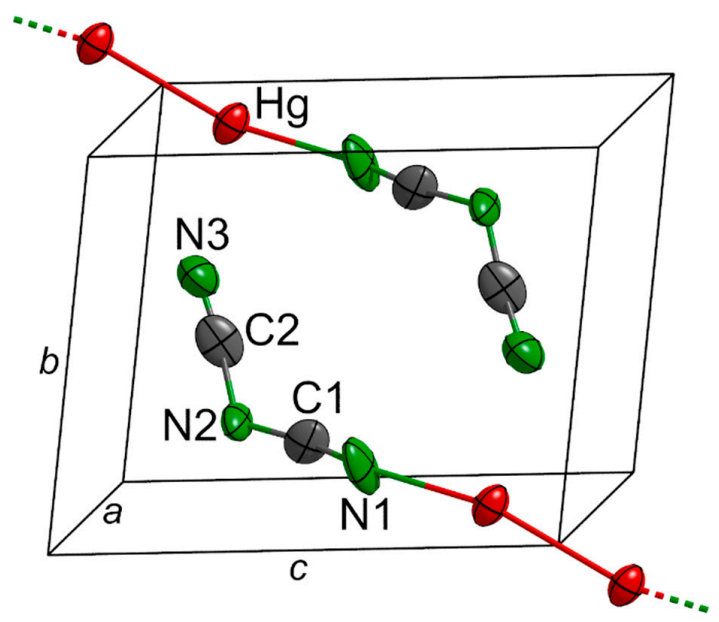

Figure 1. Crystal structure of $\mathrm{Hg}_{2}[\mathrm{dca}]_{2}$. The atomic displacement ellipsoids correspond to $90 \%$ probability using the refined anisotropic displacement parameters (ADPs).

$\mathrm{Tl}[\mathrm{dca}$ crystallizes isotypically to $\alpha-\mathrm{K}$ [dca] and $\alpha-\mathrm{Rb}[\mathrm{dca}$ [7] in the orthorhombic space group $P b c m$ (no. 57) with $a=8.5770(17), b=6.4756(13), c=7.2306(14) \AA$, and $Z=4$. This is not surprising due to the similar ionic radii of all three cations, $\mathrm{Tl}^{+}, \mathrm{K}^{+}$, and $\mathrm{Rb}^{+}$. The structure is built of layers of $\mathrm{Tl}^{+}$and [dca] ${ }^{-}$, in which $\mathrm{Tl}^{+}$is coordinated by six terminal nitrogen atoms with $d(\mathrm{Tl}-\mathrm{N} 1)=3.082(4) / 3.089(4)$ and $d(\mathrm{Tl}-\mathrm{N} 3)=2.870(4) \AA$ and two bridging nitrogen atoms with $d(\mathrm{Tl}-\mathrm{N} 2)=3.053(5) \AA$ of eight different [dca] moieties, generating a distorted square antiprism (Figure 3). These Tl-N distances are in good agreement with those that were reported for a quadratic antiprismatic coordination polyhedron in $\mathrm{TlN}_{3}$ [27] with $d(\mathrm{Tl}-\mathrm{N})=3.03 \AA$. 

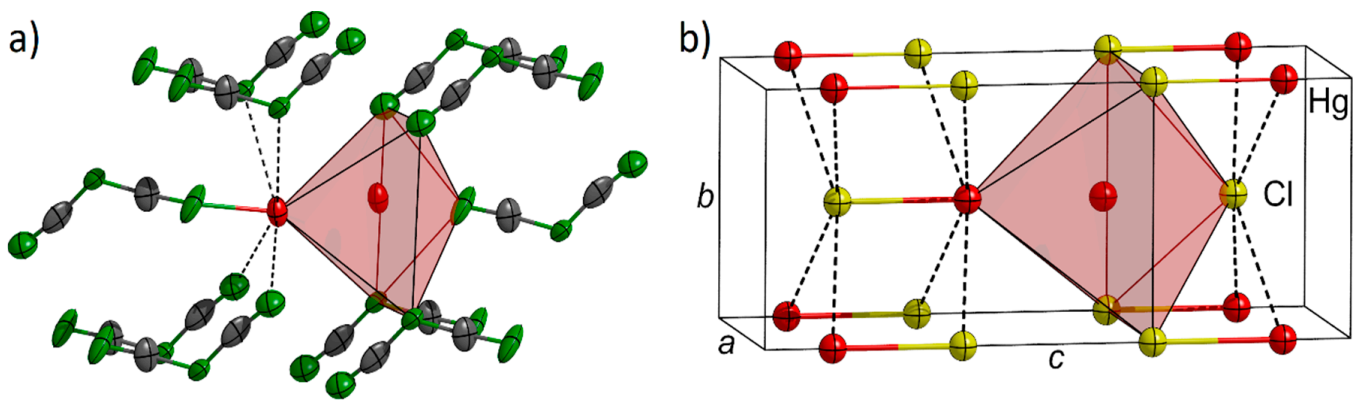

Figure 2. Comparison of the crystal structures of $\mathrm{Hg}_{2}[\mathrm{dca}]_{2}$ and calomel, $\mathrm{Hg}_{2} \mathrm{Cl}_{2}$. (a) Coordination sphere of $\mathrm{Hg}$ in $\mathrm{Hg}_{2}[\mathrm{dca}]_{2}$. The atomic displacement ellipsoids correspond to $90 \%$ probability using the refined ADPs. (b) Crystal structure of $\mathrm{Hg}_{2} \mathrm{Cl}_{2}$ [26].

a)

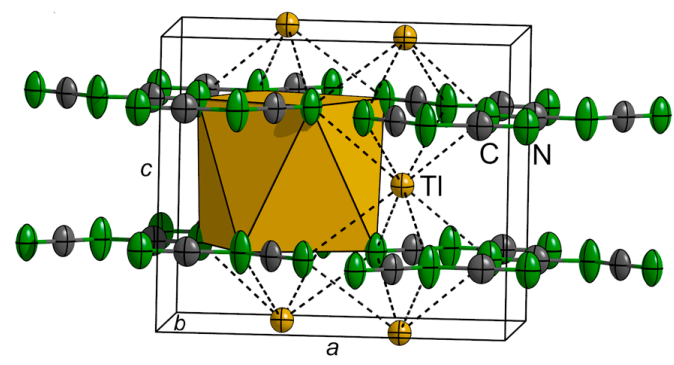

b)

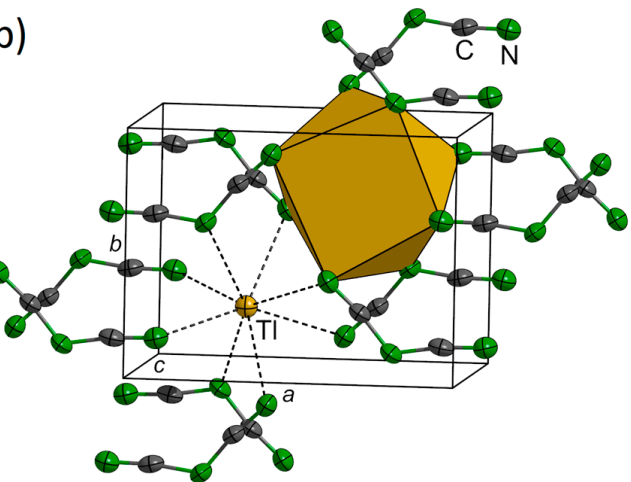

Figure 3. Crystal structure of $\mathrm{Tl}[\mathrm{dca}]$ with (a) showing the view along $c$ and (b) along $b$. The atomic displacement ellipsoids correspond to $90 \%$ probability using the refined ADPs.

Like before, the boomerang-shaped dicyanamide in $\mathrm{Tl}[\mathrm{dca}]$ exhibits atomic distances and angles in the expected range: the bond length of $d(\mathrm{C} 1-\mathrm{N} 1)=1.148(8)$ and $d(\mathrm{C} 2-\mathrm{N} 3)=1.148(7) \AA$ of the terminal $\mathrm{C}-\mathrm{N}$ pairs indicate triple bonds, while the central $\mathrm{C}-\mathrm{N}$ with $d(\mathrm{C} 1-\mathrm{N} 2)=1.316(8)$ and $d(\mathrm{C} 2-\mathrm{N} 2)=1.319(7) \AA$ of the [dca] anion are also typically found for such a moiety, with $4(\mathrm{~N} 1-\mathrm{C} 1-\mathrm{N} 2)$ $=172.0(6)^{\circ}, 4(\mathrm{~N} 2-\mathrm{C} 2-\mathrm{N} 3)=172.6(6)^{\circ}$, and $\measuredangle(\mathrm{C} 1-\mathrm{N} 2-\mathrm{C} 2)=120.6(6)^{\circ}($ Table 1$)$.

Table 1. Selected angles $\left({ }^{\circ}\right)$ and bond lengths $(\AA)$ in $\mathrm{Hg}_{2}[\mathrm{dca}]_{2}$ and $\mathrm{Tl}[\mathrm{dca}]$.

\begin{tabular}{|c|c|c|c|}
\hline $\mathrm{Hg}_{2}[\mathrm{dca}]_{2}$ & $\left({ }^{\circ}\right)$ & T1[dca] & $\left({ }^{\circ}\right)$ \\
\hline$\Varangle(\mathrm{N} 1-\mathrm{C} 1-\mathrm{N} 2)$ & $171.6(14)$ & 孔(N1-C1-N2) & $172.0(6)$ \\
\hline ব(N2-C2-N3) & $173.2(13)$ & Ł(N2-C2-N3) & $172.6(6)$ \\
\hline$\Varangle(\mathrm{C} 1-\mathrm{N} 2-\mathrm{C} 2)$ & $119.4(10)$ & $\Varangle(\mathrm{C} 1-\mathrm{N} 2-\mathrm{C} 2)$ & $120.6(5)$ \\
\hline \multicolumn{3}{|c|}{ (̊̊) } & (@) \\
\hline N1-C1 & $1.148(14)$ & $\mathrm{N} 1-\mathrm{C} 1$ & $1.148(8)$ \\
\hline $\mathrm{C} 1-\mathrm{N} 2$ & $1.325(13)$ & $\mathrm{C} 1-\mathrm{N} 2$ & $1.316(8)$ \\
\hline N2-C2 & $1.317(16)$ & N2-C2 & $1.319(7)$ \\
\hline $\mathrm{C} 2-\mathrm{N} 3$ & $1.108(16)$ & $\mathrm{C} 2-\mathrm{N} 3$ & $1.148(7)$ \\
\hline $\mathrm{Hg}-\mathrm{Hg}$ & $2.518(3)$ & $\mathrm{Tl}-\mathrm{Tl}(2 \times)$ & $3.6153(7)$ \\
\hline $\mathrm{Hg}-\mathrm{N} 1$ & $2.166(10)$ & $\mathrm{Tl}-\mathrm{Tl}(2 \times)$ & $4.5129(7)$ \\
\hline $\mathrm{Hg}-\mathrm{N} 2$ & $3.412(11)$ & Tl-N1 $(2 \times)$ & $3.089(4)$ \\
\hline $\mathrm{Hg}-\mathrm{N} 2$ & $3.084(9)$ & Tl-N1 $(2 \times)$ & $3.082(4)$ \\
\hline $\mathrm{Hg}-\mathrm{N} 3$ & $2.612(12)$ & Tl-N2 $(2 \times)$ & $3.053(5)$ \\
\hline $\mathrm{Hg}-\mathrm{N} 3$ & $2.834(10)$ & Tl-N3 $(2 \times)$ & $2.870(4)$ \\
\hline
\end{tabular}

Given the large number of structurally characterized dicyanamides, it is tempting to finally investigate their volume chemistry. Hence, we calculated the volume increment of the dicyanamide anion according to the method of Biltz, that is, taking into account the tabulated volume increments [28] 
of the monovalent cations $\mathrm{M}^{+}$, namely those of $\mathrm{Li}, \mathrm{Na}, \mathrm{K}, \mathrm{Rb}, \mathrm{Cs}, \mathrm{Cu}, \mathrm{Ag}, \mathrm{Hg}, \mathrm{Tl}$, and $\mathrm{NH}_{4}$. As shown in Table 2, the dicyanamide anion has a volume of $44.3(17) \mathrm{cm}^{3} \cdot \mathrm{mol}^{-1}$ on average, so it is about $70 \%$ larger than the $\mathrm{NCN}^{2-}$ cyanamide anion $\left(26 \mathrm{~cm}^{3} \cdot \mathrm{mol}^{-1}\right)$ [29] That being said, the dicyanamide anion appears as a mid-heavy $(66.04 \mathrm{u})$ but relatively spacious pseudohalide, and it finalizes the trend found [28] for the true halides $\left(\mathrm{F}^{-}: 9.5, \mathrm{Cl}^{-}: 20, \mathrm{Br}^{-}: 25, \mathrm{I}^{-}: 34,[\mathrm{dca}]^{-}: 44 \mathrm{~cm}^{3} \cdot \mathrm{mol}^{-1}\right)$. For completeness, we add that the calculated [dca $]^{-}$volume increments for $\mathrm{Hg}_{2}[\mathrm{dca}]_{2}$ and $\mathrm{Tl}[\mathrm{dca}]\left(40.2\right.$ and $\left.41.9 \mathrm{~cm}^{3} \cdot \mathrm{mol}^{-1}\right)$ appear as slightly smaller, which is probably due to the fact that these crystal structures were determined at a lower temperature (Table 2).

Table 2. Calculated molar volumes of $[\mathrm{dca}]^{-}$based on $M[\mathrm{dca}]$ crystal structures containing monovalent cations.

\begin{tabular}{|c|c|c|c|c|c|}
\hline$M[$ dca $]$ & $\begin{array}{l}\text { Cell Volume } \\
\qquad\left(\AA^{3}\right), Z\end{array}$ & $T(\mathrm{~K})$ & $\begin{array}{l}\text { Molar Volume } \\
\left(\mathrm{cm}^{3} \cdot \mathrm{mol}^{-1}\right)\end{array}$ & $\begin{array}{c}M^{+} \text {Volume } \\
\left(\mathrm{cm}^{3} \cdot \mathrm{mol}^{-1}\right)[28]\end{array}$ & $\begin{array}{c}{[\text { dca }]^{-} \text {Volume }} \\
\left(\mathrm{cm}^{3} \cdot \mathrm{mol}^{-1}\right)\end{array}$ \\
\hline $\mathrm{NH}_{4}[$ dca] [4] & $428.32,4$ & 200 & 64.5 & 19.5 & 45.0 \\
\hline Li[dca] [5] & $313.84,4$ & 170 & 47.2 & 1.5 & 45.7 \\
\hline $\mathrm{Na}$ [dca] [8] & $345.25,4$ & 293 & 52.0 & 6.5 & 45.5 \\
\hline$\alpha-\mathrm{K}[\mathrm{dca}][7]$ & $390.31,4$ & 293 & 58.7 & 16 & 42.7 \\
\hline$\beta$-K[dca] [7] & $416.78,4$ & 293 & 62.7 & 16 & 46.7 \\
\hline$\gamma$-K[dca] [7] & $415.56,4$ & 293 & 62.5 & 16 & 46.5 \\
\hline$\alpha-\mathrm{Rb}[\mathrm{dca}][7]$ & $433.4,4$ & 293 & 65.2 & 20 & 45.2 \\
\hline$\beta-\mathrm{Rb}[\mathrm{dca}]$ [7] & $1778.31,16$ & 293 & 66.9 & 20 & 46.9 \\
\hline Cs[dca] [6] & $919.74,8$ & 299 & 69.2 & 26 & 43.2 \\
\hline $\mathrm{Cu}[\mathrm{dca}][12]$ & $332.21,4$ & 248 & 50.0 & 5 & 45.0 \\
\hline Ag[dca], o [14] & $349.24,4$ & 293 & 52.6 & 9 & 43.6 \\
\hline Ag[dca $], \operatorname{tr}[14]$ & $256.36,3$ & 293 & 51.4 & 9 & 42.4 \\
\hline $\mathrm{Hg}_{2}[\mathrm{dca}]_{2}$ & $186.84,1$ & 100 & 112.4 & 16 & 40.2 \\
\hline $\mathrm{Tl}[\mathrm{dca}]$ & $401.60,4$ & 100 & 60.4 & 18.5 & 41.9 \\
\hline
\end{tabular}

\subsection{IR-Spectra}

The vibrational frequencies, as obtained from the IR spectra of the title compounds, confirm the presence of the [dca] group (Table 3, Figure 4).

Table 3. IR data of $\mathrm{Hg}_{2}[\mathrm{dca}]_{2}$ and $\mathrm{Tl}[\mathrm{dca}]$. All numbers are given in $\mathrm{cm}^{-1}$.

\begin{tabular}{ccc}
\hline Vibration & $\boldsymbol{v}\left(\mathbf{H g}_{2}\left[\mathbf{d c a}_{\mathbf{2}}\right)\right.$ & $\boldsymbol{v}(\mathbf{T l}[\mathbf{d c a}])$ \\
\hline$\sigma_{\mathrm{as}}(\mathrm{N}-\mathrm{C} \equiv \mathrm{N})$ & $493 / 515$ & 517 \\
$\sigma_{\mathrm{s}}(\mathrm{N}-\mathrm{C} \equiv \mathrm{N})$ & 662 & 656 \\
$v_{\mathrm{s}}(\mathrm{N}-\mathrm{C})$ & 934 & 905 \\
$v_{\mathrm{as}}(\mathrm{N}-\mathrm{C})$ & 1354 & 1323 \\
$v_{\mathrm{as}}(\mathrm{N} \equiv \mathrm{C})$ & 2171 & 2119 \\
$v_{\mathrm{as}}(\mathrm{N}-\mathrm{C})+v_{\mathrm{s}}(\mathrm{N}-\mathrm{C})$ & 2243 & 2191 \\
$v_{\mathrm{s}}(\mathrm{N} \equiv \mathrm{C})$ & 2301 & 2247 \\
$v_{\mathrm{as}}(\mathrm{N} \equiv \mathrm{C})+v_{\mathrm{s}}(\mathrm{N}-\mathrm{C})$ & 3072 & $3010 / 2972$ \\
$v_{\mathrm{s}}(\mathrm{N} \equiv \mathrm{C})+v_{\text {as }}(\mathrm{N}-\mathrm{C})$ & 3577 & 3508 \\
\hline
\end{tabular}
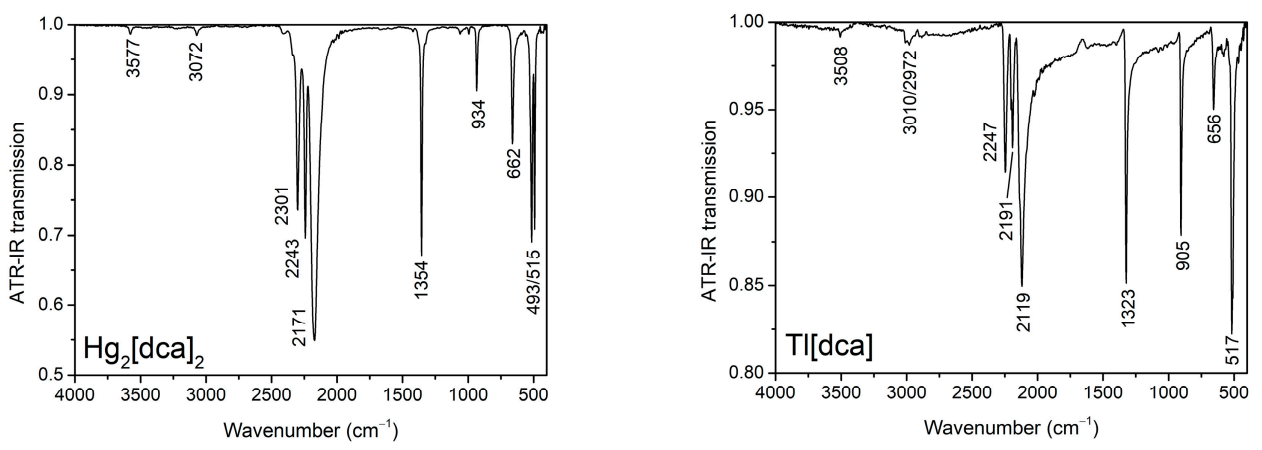

Figure 4. Infrared spectra of $\mathrm{Hg}_{2}[\mathrm{dca}]_{2}$ (left) and $\mathrm{Tl}[\mathrm{dca}]$ (right). 


\section{Materials and Methods}

\subsection{Syntheses}

Crystalline powder of $\mathrm{Hg}_{2}$ [dca $]_{2}$ was synthesized by mixing stoichiometric amounts of $\mathrm{Na}$ [dca] and $\mathrm{Hg}_{2}\left(\mathrm{NO}_{3}\right)_{2} \cdot 2 \mathrm{H}_{2} \mathrm{O}$ in water, followed by precipitation, but the fine powder was unsuitable for single-crystal diffraction. Better crystals of $\mathrm{Hg}_{2}[\mathrm{dca}]_{2}$ were subsequently obtained by a diffusion reaction. An aqueous solution of $\mathrm{Hg}_{2}\left(\mathrm{NO}_{3}\right)_{2} \cdot 2 \mathrm{H}_{2} \mathrm{O}(5 \mathrm{~mL}, c=0.05 \mathrm{M})$ was layered below, and another aqueous solution of $\mathrm{Na}$ [dca] $(5 \mathrm{~mL}, c=0.1 \mathrm{M})$ was layered above an aqueous solution of $\mathrm{NaNO}_{3}(5 \mathrm{~mL}$, $c=0.22 \mathrm{M}$ ) in a regular test-tube. Colorless, transparent crystals of $\mathrm{Hg}_{2}[\mathrm{dca}]_{2}$ grew within two days in the region between the layers of $\mathrm{Hg}_{2}\left(\mathrm{NO}_{3}\right)_{2}$ and $\mathrm{NaNO}_{3}$.

$\mathrm{Tl}[\mathrm{dca}]$ was obtained by adding $\mathrm{TlBr}(184.8 \mathrm{mg}, 0.65 \mathrm{mmol})$ to an aqueous Ag[dca] (120.5 mg, $0.69 \mathrm{mmol}, 5 \mathrm{~mL}$ deionized $\mathrm{H}_{2} \mathrm{O}$ ) suspension. The synthesis of $\mathrm{Ag}$ [dca] has been described in a previous paper [23]. The suspension was stirred for twelve hours under the exclusion of light. $1 \mathrm{~mL}$ of the silver bromide-free solution was taken, and the water was evaporated in a desiccator. A colorless, transparent, orthorhombic crystal of Tl[dca] suitable for single-crystal X-ray diffraction was selected for diffraction data collection.

\subsection{Single Crystal Diffraction}

A suitable single crystal of $\mathrm{Hg}_{2}\left[\mathrm{dca}_{2}\right.$ was mounted on a glass fiber. Intensity data were collected with a STOE STADIVARI Dectris Pilatus 200K detector (STOE \& Cie GmbH, Darmstadt, Germany), equipped with a GeniX Mo High Flux source (Mo $K \alpha$ radiation, $\lambda=0.71073 \AA$, multilayer optics). Temperature control was achieved using an Oxford Cryostream 800 (Oxford Cryosystems Ltd., Oxford, UK) at $100 \mathrm{~K}$. Collected data were integrated with X-Area Integrate [30], and Gaussian-integration absorption corrections were applied with STOE X-Red [31]. The structure was solved by charge-flipping methods (Superflip [32]) and refined on $F^{2}$, as implemented in Jana2006 [33]. More crystallographic details can be found in Tables 4-6. The goodness-of-fit is unusually large (3.60) and it probably goes back to the rather high absorption coefficient for Mo $\mathrm{K} \alpha$ radiation resulting in an imperfect absorption model.

Table 4. Summary of single-crystal X-ray diffraction structure determination data of Tl[dca] and $\mathrm{Hg}_{2}[\mathrm{dca}]_{2}$.

\begin{tabular}{ccc}
\hline Chemical Formula & $\mathrm{Hg}_{2}[\mathrm{dca}]_{2}$ & TI[dca] \\
\hline Formula weight $\left(\mathrm{g} \cdot \mathrm{mol}^{-1}\right)$ & 533.3 & 270.42 \\
Crystal system & triclinic & orthorhombic \\
Space group & $P \overline{1}($ no. 2$)$ & Pbcm $($ no. 57$)$ \\
Temperature $(\mathrm{K})$ & $100(2)$ & $100(2)$ \\
$a(\AA)$ & $3.7089(5)$ & $8.5770(17)$ \\
$b(\AA)$ & $6.4098(6)$ & $6.4756(13)$ \\
$c(\AA)$ & $8.150(6)$ & $7.2306(14)$ \\
$\alpha\left(^{\circ}\right)$ & $81.575(6)$ & 90 \\
$\beta\left(^{\circ}\right)$ & $80.379(7)$ & 90 \\
$\gamma\left(\left(^{\circ}\right)\right.$ & $80.195(7)$ & 90 \\
$V\left(\AA^{3}\right)$ & $186.84(14)$ & $401.60(14)$ \\
$Z$ & 1 & 4 \\
Radiation, $\lambda(\AA)$ & Mo K $\alpha, 0.71073$ & Mo K $\alpha, 0.71073$ \\
$\mu\left(\mathrm{mm}^{-1}\right)$ & 41.09 & 40.022 \\
Crystal shape and color & Colorless block & Colorless block \\
Crystal size $\left(\mathrm{mm}^{3}\right)$ & $0.17 \times 0.08 \times 0.02$ & $0.05 \times 0.04 \times 0.02$ \\
$\rho_{\text {calcd }}\left(\mathrm{g} \cdot \mathrm{cm}^{-3}\right)$ & 4.739 & 4.473 \\
Diffractometer & STOE STADIVARI with Hybrid Pixel & Bruker AXS Enraf-Nonius with \\
Absorption correction & Counting Detector & KappaCCD Detector \\
\hline
\end{tabular}


Table 4. Cont.

\begin{tabular}{ccc}
\hline Chemical Formula & $\mathrm{Hg}_{2}[\mathrm{dca}]_{2}$ & Tl[dca] \\
\hline$T_{\min }, T_{\max }$ & $0.0672,0.6730$ & $0.15236,0.46282$ \\
No. of measured, & 3671 & 8880 \\
independent and observed & 1263 & 816 \\
{$[I>3 \sigma(I)]$ reflections } & 1154 & 549 \\
$R_{\text {obs }}$ & 4.68 & 1.87 \\
$w R 2_{\text {obs }}$ & 10.88 & 3.94 \\
$R_{\text {all }}$ & 4.92 & 3.25 \\
$w R 2_{\text {all }}$ & 10.91 & 4.46 \\
GOF & 3.60 & 1.09 \\
No. of parameters, restraints & 55,0 & 36,0 \\
\hline
\end{tabular}

Table 5. Atomic coordinates (all on $2 i$ ) and equivalent isotropic displacement parameters $U_{\text {eq }}\left(\AA^{2}\right)$ of $\mathrm{Hg}_{2}[\mathrm{dca}]_{2}$.

\begin{tabular}{ccccc}
\hline Atom & $x$ & $y$ & $z$ & $U_{\text {eq }}$ \\
\hline $\mathrm{Hg}$ & $0.96205(10)$ & $0.90300(6)$ & $0.14632(4)$ & $0.01463(12)$ \\
$\mathrm{N} 1$ & $0.923(3)$ & $0.805(2)$ & $0.4137(12)$ & $0.024(3)$ \\
$\mathrm{N} 2$ & $0.619(3)$ & $0.7427(15)$ & $0.7062(10)$ & $0.015(2)$ \\
$\mathrm{N} 3$ & $0.406(3)$ & $0.4138(17)$ & $0.8391(12)$ & $0.020(3)$ \\
$\mathrm{C} 1$ & $0.765(3)$ & $0.7693(19)$ & $0.5460(13)$ & $0.016(3)$ \\
$\mathrm{C} 2$ & $0.510(3)$ & $0.559(2)$ & $0.7710(14)$ & $0.018(3)$ \\
\hline
\end{tabular}

Table 6. Anisotropic displacement parameters $U_{\mathrm{ij}}\left(\AA^{2}\right)$ of $\mathrm{Hg}_{2}[\mathrm{dca}]_{2}$.

\begin{tabular}{ccccccc}
\hline Atom & $\boldsymbol{U}_{\mathbf{1 1}}$ & $\boldsymbol{U}_{\mathbf{2 2}}$ & $\boldsymbol{U}_{\mathbf{3 3}}$ & $\boldsymbol{U}_{\mathbf{2 3}}$ & $\boldsymbol{U}_{\mathbf{1 3}}$ & $\boldsymbol{U}_{\mathbf{1 2}}$ \\
\hline $\mathrm{Hg}$ & $0.01303(19)$ & $0.0173(2)$ & $0.01206(19)$ & $-0.00301(13)$ & $0.00010(12)$ & $0.00189(13)$ \\
$\mathrm{N} 1$ & $0.026(5)$ & $0.038(6)$ & $0.011(4)$ & $-0.014(4)$ & $0.005(3)$ & $-0.012(4)$ \\
$\mathrm{N} 2$ & $0.023(4)$ & $0.012(4)$ & $0.009(3)$ & $0.001(3)$ & $-0.001(3)$ & $-0.004(3)$ \\
$\mathrm{N} 3$ & $0.025(5)$ & $0.018(5)$ & $0.018(4)$ & $-0.005(4)$ & $-0.002(3)$ & $-0.006(3)$ \\
$\mathrm{C} 1$ & $0.008(4)$ & $0.022(5)$ & $0.018(4)$ & $-0.005(4)$ & $0.000(3)$ & $0.000(4)$ \\
$\mathrm{C} 2$ & $0.006(4)$ & $0.027(6)$ & $0.020(5)$ & $-0.002(4)$ & $0.004(3)$ & $-0.010(4)$ \\
\hline
\end{tabular}

A suitable single crystal of $\mathrm{Tl}[\mathrm{dca}]$ was adhered to a $100 \mu \mathrm{m}$ MiTeGen loop using perfluoropolyether PFO-XR75. Intensity data were collected on a FR 591 rotating anode that was equipped with an Incoatec Helios focusing multilayer optic (Mo K $\alpha$ radiation, $\lambda=0.71073 \AA$ ) and a Bruker AXS Enraf-Nonius KappaCCD detector (Bruker AXS GmbH, Karlsruhe, Germany). The temperature of the crystal was maintained at $100 \mathrm{~K}$ using an Oxford Cryostream 700 (Oxford Cryosystems Ltd., Oxford, United Kingdom). Diffraction data were integrated with the program REVALCCD ver. 1.6, 2008 and a Gaussian integration absorption correction based on the crystal shape was applied using SADABS [34]. Data preparation and reciprocal space exploration were performed by XPREP [35]. The structure was solved with SHELXT [36] by a dual-space method and was refined on $F^{2}$, as implemented in SHELXL [37]. Crystallographic details can be found in Tables 4, 7 and 8.

Additional details concerning the structure determination are available in CIF format (see Supplementary Materials) and have been deposited under the CCDC entry numbers 1881933 for $\mathrm{Tl}[\mathrm{dca}]$ and 1881934 for $\mathrm{Hg}_{2}[\mathrm{dca}]_{2}$. Copies of the data can be obtained free of charge from CCDC (http://www.ccdc.cam.ac.uk/conts/retrieving.html).

Table 7. Atomic coordinates and equivalent isotropic displacement parameters $U_{\text {eq }}\left(\AA^{2}\right)$ of $\operatorname{Tl}[\mathrm{dca}]$.

\begin{tabular}{cccccc}
\hline Atom & Site & $x$ & $y$ & $z$ & $U_{\text {eq }}$ \\
\hline $\mathrm{T} 1$ & $4 c$ & $0.31674(2)$ & $1 / 4$ & $1 / 2$ & $0.01287(6)$ \\
$\mathrm{N} 1$ & $4 d$ & $0.5898(6)$ & $0.3835(8)$ & $3 / 4$ & $0.0183(10)$ \\
$\mathrm{N} 2$ & $4 d$ & $0.7848(7)$ & $0.1054(9)$ & $3 / 4$ & $0.0218(12)$ \\
$\mathrm{N} 3$ & $4 d$ & $0.0707(6)$ & $0.1391(8)$ & $3 / 4$ & $0.0194(10)$ \\
$\mathrm{C} 1$ & $4 d$ & $0.6880(5)$ & $0.2630(11)$ & $3 / 4$ & $0.0144(10)$ \\
$\mathrm{C} 2$ & $4 d$ & $0.9369(7)$ & $0.1356(9)$ & $3 / 4$ & $0.0150(10)$ \\
\hline
\end{tabular}


Table 8. Anisotropic displacement parameters $U_{\mathrm{ij}}\left(\AA^{2}\right)$ of Tl[dca].

\begin{tabular}{ccccccc}
\hline Atom & $\boldsymbol{U}_{\mathbf{1 1}}$ & $\boldsymbol{U}_{\mathbf{2 2}}$ & $\boldsymbol{U}_{\mathbf{3 3}}$ & $\boldsymbol{U}_{\mathbf{2 3}}$ & $\boldsymbol{U}_{\mathbf{1 3}}$ & $\boldsymbol{U}_{\mathbf{1 2}}$ \\
\hline $\mathrm{T} 1$ & $0.01236(9)$ & $0.01241(10)$ & $0.01384(9)$ & $-0.00016(13)$ & 0 & 0 \\
$\mathrm{~N} 1$ & $0.0111(19)$ & $0.013(2)$ & $0.031(3)$ & 0 & 0 & $-0.002(2)$ \\
$\mathrm{N} 2$ & $0.012(2)$ & $0.010(2)$ & $0.043(4)$ & 0 & 0 & $-0.003(2)$ \\
$\mathrm{N} 3$ & $0.015(2)$ & $0.012(2)$ & $0.031(3)$ & 0 & 0 & $0.0007(19)$ \\
$\mathrm{C} 1$ & $0.012(2)$ & $0.009(3)$ & $0.022(3)$ & 0 & 0 & $-0.003(3)$ \\
$\mathrm{C} 2$ & $0.017(3)$ & $0.008(2)$ & $0.020(3)$ & 0 & 0 & $-0.002(2)$ \\
\hline
\end{tabular}

\subsection{Infrared Spectra}

The IR spectra were recorded using an ALPHA II FT-IR-spectrometer (Bruker Optik GmbH, Ettlingen, Germany), equipped with an ATR Platinum Diamond measuring cell. All measurements were undertaken within the range of 4000 to $400 \mathrm{~cm}^{-1}$.

\section{Conclusions}

The compounds $\mathrm{Hg}_{2}[\mathrm{dca}]_{2}$ and $\mathrm{Tl}[\mathrm{dca}]$ were synthesized, their respective crystal structures were determined, and their IR spectra were measured. While the structure of $\mathrm{Hg}_{2}[\mathrm{dca}]_{2}$ shows similarities to the structure of $\mathrm{Hg}_{2} \mathrm{Cl}_{2}, \mathrm{Tl}[\mathrm{dca}$ ] is isostructural to $\alpha-\mathrm{K}$ [dca] and $\alpha-\mathrm{Rb}$ [dca]. The [dca] pseudohalide exceeds $\mathrm{I}^{-}$in its volume increment. The acquired data of the IR spectra are similar to the data of the previously reported dicyanamides.

Supplementary Materials: The following are available online at http:/ /www.mdpi.com/2304-6740/6/4/135/s1: CIF and CIFchecked files.

Author Contributions: M.M. and O.R. conceived and designed the experiment; M.M. performed the syntheses, ATR-IR experiments and the single-crystal X-ray diffraction (SXRD) of $\mathrm{Hg}_{2}[\mathrm{dca}]_{2}$; N.N. and R.G. performed the SXRD of TI[dca]; results were discussed with all authors; M.M. wrote the paper in collaboration with all co-authors.

Funding: This research received no external funding.

Acknowledgments: Nils Nöthling and Richard Goddard would like to thank Martin Jäger and Joachim Horst, Labor für Instrumentelle und Umweltschutzanalytik, Hochschule Niederrhein, Krefeld, Germany, for helpful discussions.

Conflicts of Interest: The authors declare no conflict of interest.

\section{References}

1. Scholz, T.; Görne, A.L.; Dronskowski, R. Itinerant nitrides and salt-like guanidinates-The diversity of solid-state nitrogen chemistry. Prog. Solid State Chem. 2018, 51, 1-18. [CrossRef]

2. Sougrati, M.T.; Arayamparambil, J.J.; Liu, X.; Mann, M.; Slabon, A.; Stievano, L.; Dronskowski, R. Carbodiimides as energy materials: Which directions for a reasonable future? J. Chem. Soc. Dalton Trans. 2018, 47, 10827-10832. [CrossRef] [PubMed]

3. Sougrati, M.T.; Darwiche, A.; Liu, X.; Mahmoud, A.; Hermann, R.P.; Jouen, S.; Monconduit, L.; Dronskowski, R.; Stievano, L. Transition-Metal Carbodiimides as Molecular Negative Electrode Materials for Lithium- and Sodium-Ion Batteries with Excellent Cycling Properties. Angew. Chem. Int. Ed. 2016, 55, 5090-5095. [CrossRef] [PubMed]

4. Jürgens, B.; Höppe, H.A.; Irran, E.; Schnick, W. Transformation of Ammonium Dicyanamide into Dicyandiamide in the Solid. Inorg. Chem. 2002, 41, 4849-4851. [CrossRef] [PubMed]

5. Reckeweg, O.; DiSalvo, F.J.; Schulz, A.; Blaschkowski, B.; Jagiella, S.; Schleid, T. Synthesis, Crystal Structure, and Vibrational Spectra of the Anhydrous Lithium Dicyanamide $\mathrm{Li}\left[\mathrm{N}(\mathrm{CN})_{2}\right]$. Z. Anorg. Allg. Chem. 2014, 640, 851-855. [CrossRef]

6. Starynowicz, P. Structure of caesium dicyanamide. Acta Crystallogr. Sect. C Cryst. Struct. Commun. 1991, 47, 2198-2199. [CrossRef] 
7. Irran, E.; Jürgens, B.; Schnick, W. Trimerization of alkali dicyanamides $M\left[\mathrm{~N}(\mathrm{CN})_{2}\right]$ and formation of tricyanomelaminates $M_{3}\left[\mathrm{C}_{6} \mathrm{~N}_{9}\right](M=\mathrm{K}, \mathrm{Rb})$ in the melt: Crystal structure determination of three polymorphs of $\mathrm{K}\left[\mathrm{N}(\mathrm{CN})_{2}\right]$, two of $\mathrm{Rb}\left[\mathrm{N}(\mathrm{CN})_{2}\right]$, and one of $\mathrm{K}_{3}\left[\mathrm{C}_{6} \mathrm{~N}_{9}\right]$ and $\mathrm{Rb}_{3}\left[\mathrm{C}_{6} \mathrm{~N}_{9}\right]$ from X-ray powder diffractometry. Chem. Eur. J. 2001, 7, 5372-5381. [PubMed]

8. Jürgens, B.; Irran, E.; Schneider, J.; Schnick, W. Trimerization of $\mathrm{NaC}_{2} \mathrm{~N}_{3}$ to $\mathrm{Na}_{3} \mathrm{C}_{6} \mathrm{~N}_{9}$ in the Solid: $\mathrm{Ab}$ Initio Crystal Structure Determination of Two Polymorphs of $\mathrm{NaC}_{2} \mathrm{~N}_{3}$ and of $\mathrm{Na}_{3} \mathrm{C}_{6} \mathrm{~N}_{9}$ from X-ray Powder Diffractometry. Inorg. Chem. 2000, 39, 665-670. [CrossRef] [PubMed]

9. Jürgens, B.; Irran, E.; Schnick, W. Syntheses, Vibrational Spectroscopy, and Crystal Structure Determination from X-Ray Powder Diffraction Data of Alkaline Earth Dicyanamides $M\left[N(C N)_{2}\right]_{2}$ with $M=\mathrm{Mg}, \mathrm{Ca}, \mathrm{Sr}$, and Ba. J. Solid State Chem. 2001, 157, 241-249. [CrossRef]

10. Manson, J.L.; Kmety, C.R.; Epstein, A.J.; Miller, J.S. Spontaneous Magnetization in the $M\left[N(C N)_{2}\right]_{2}(M=C r$, Mn) Weak Ferromagnets. Inorg. Chem. 1999, 38, 2552-2553. [CrossRef]

11. Manson, J.L.; Kmety, C.R.; Huang, Q.-Z.; Lynn, J.W.; Bendele, G.M.; Pagola, S.; Stephens, P.W.; Liable-Sands, L.M.; Rheingold, A.L.; Epstein, A.J.; et al. Structure and Magnetic Ordering of $M^{\mathrm{II}}\left[\mathrm{N}(\mathrm{CN})_{2}\right]_{2}$ ( $M=\mathrm{Co}, \mathrm{Ni})$. Chem. Mater. 1998, 10, 2552-2560. [CrossRef]

12. Reckeweg, O.; Dinnebier, R.E.; Schulz, A.; Blaschkowski, B.; Schneck, C.; Schleid, T. About the air- and water-stable copper(I) dicyanamide: Synthesis, crystal structure, vibrational spectra and DSC/TG analysis of $\mathrm{Cu}\left[\mathrm{N}(\mathrm{CN})_{2}\right.$ ]. Z. Naturforsch. B Chem. Sci. 2017, 72, 159-165. [CrossRef]

13. Hodgson, S.A.; Hunt, S.J.; Sørensen, T.J.; Thompson, A.L.; Reynolds, E.M.; Faulkner, S.; Goodwin, A.L. Anomalous Thermal Expansion and Luminescence Thermochromism in Silver(I) Dicyanamide. Eur. J. Inorg. Chem. 2016, 2016, 4378-4381. [CrossRef]

14. Reckeweg, O.; Schulz, A.; Schneck, C.; Lissner, F.; Schleid, T. Syntheses, single-crystal structures, vibrational spectra and DSC/TG analyses of orthorhombic and trigonal $\operatorname{Ag}\left[\mathrm{N}(\mathrm{CN})_{2}\right]$. Z. Naturforsch. B Chem. Sci. 2016, 71, 827-834. [CrossRef]

15. Manson, J.L.; Lee, D.W.; Rheingold, A.L.; Miller, J.S. Buckled-layered Structure of Zinc Dicyanamide, $\mathrm{Zn}{ }^{\mathrm{II}}\left[\mathrm{N}(\mathrm{CN})_{2}\right]_{2}$. Inorg. Chem. 1998, 37, 5966-5967. [CrossRef] [PubMed]

16. Jürgens, B.; Irran, E.; Höppe, H.A.; Schnick, W. Phase Transition of a Dicyanamide with Rutile-like Structure: Syntheses and Crystal Structures of $\alpha$ - and $\beta-\mathrm{Cd}\left[\mathrm{N}(\mathrm{CN})_{2}\right]_{2}$. Z. Anorg. Allg. Chem. 2004, 630, $219-223$. [CrossRef]

17. Jürgens, B.; Irran, E.; Schnick, W. Synthesis and characterization of the rare-earth dicyanamides $\operatorname{Ln}\left[\mathrm{N}(\mathrm{CN})_{2}\right]_{3}$ with $L n=\mathrm{La}, \mathrm{Ce}, \mathrm{Pr}, \mathrm{Nd}, \mathrm{Sm}$, and Eu. J. Solid State Chem. 2005, 178, 72-78. [CrossRef]

18. Nag, A.; Schmidt, P.J.; Schnick, W. Synthesis and Characterization of $\mathrm{Tb}\left[\mathrm{N}(\mathrm{CN})_{2}\right]_{3} \cdot 2 \mathrm{H}_{2} \mathrm{O}$ and $\mathrm{Eu}\left[\mathrm{N}(\mathrm{CN})_{2}\right]_{3} \cdot 2 \mathrm{H}_{2} \mathrm{O}$ : Two New Luminescent Rare-Earth Dicyanamides. Chem. Mater. 2006, 18, 5738-5745. [CrossRef]

19. Nag, A.; Schnick, W. Synthesis, Crystal Structure and Thermal Behavior of Gadolinium Dicyanamide Dihydrate $\mathrm{Gd}\left[\mathrm{N}(\mathrm{CN})_{2}\right]_{3} \cdot 2 \mathrm{H}_{2} \mathrm{O}$. Z. Anorg. Allg. Chem. 2006, 632, 609-614. [CrossRef]

20. Reckeweg, O.; Wakabayashi, R.H.; DiSalvo, F.J.; Schulz, A.; Schneck, C.; Schleid, T. About alkali metal dicyanamides: Syntheses, single-crystal structure determination, DSC/TG and vibrational spectra of $\mathrm{KCs}\left[\mathrm{N}(\mathrm{CN})_{2}\right]_{2}$ and $\mathrm{NaRb}_{2}\left[\mathrm{~N}(\mathrm{CN})_{2}\right]_{3} \cdot \mathrm{H}_{2} \mathrm{O}$. Z. Naturforsch. B Chem. Sci. 2015, 70, 365-372. [CrossRef]

21. Reckeweg, O.; DiSalvo, F.J. Synthesis and single-crystal structure of the pseudo-ternary compounds $\mathrm{Li} A\left[\mathrm{~N}(\mathrm{CN})_{2}\right]_{2}(A=\mathrm{K}$ or Rb). Z. Naturforsch. B Chem. Sci. 2016, 71, 157-160. [CrossRef]

22. Jürgens, B.; Milius, W.; Morys, P.; Schnick, W. Trimerisierung von Dicyanamid-Ionen $\mathrm{C}_{2} \mathrm{~N}_{3}^{-}$im Festkörper-Synthesen, Kristallstrukturen und Eigenschaften von $\mathrm{NaCs}_{2}\left(\mathrm{C}_{2} \mathrm{~N}_{3}\right)_{3}$ und $\mathrm{Na}_{3} \mathrm{C}_{6} \mathrm{~N}_{9} \cdot 3 \mathrm{H}_{2} \mathrm{O}$. Z. Anorg. Allg. Chem. 1998, 624, 91-97. [CrossRef]

23. Mann, M.; Reckeweg, O.; Dronskowski, R. Synthesis and Characterization of the New Dicyanamide $\mathrm{LiCs}_{2}\left[\mathrm{~N}(\mathrm{CN})_{2}\right]_{3}$. Inorganics 2018, 6, 108. [CrossRef]

24. Madelung, W.; Kern, E. Über Dicyanamid. Justus Liebigs Ann. Chem. 1922, 427, 1-26. [CrossRef]

25. Kuhn, M.; Mecke, R. IR-Spektroskopische Untersuchungen am Dicyanamid-Anion, $\left[\mathrm{N}(\mathrm{CN})_{2}\right]^{-}$. Chem. Ber. 1961, 94, 3010-3015. [CrossRef]

26. Dorm, E. Studies on the Crystal Chemistry of the Mercurous Ion and of Mercurous Salts; Stockholm Univ.: Stockholm, Sweden, 1970; pp. 1-25.

27. Reckeweg, O.; Simon, A. Azide und Cyanamide-Ähnlich und doch anders/Azides and Cyanamides-Similar and Yet Different. Z. Naturforsch. B Chem. Sci. 2003, 58, 1097-1104. [CrossRef] 
28. Biltz, W. Raumchemie der festen Stoffe; Verlag von Leopold Voss: Leipzig, Germany, 1934.

29. Stork, L.; Liu, X.; Fokwa, B.P.T.; Dronskowski, R. Crystal Structure Determination of Thallium Carbodiimide, $\mathrm{Tl}_{2}$ NCN. Z. Anorg. Allg. Chem. 2007, 633, 1339-1342. [CrossRef]

30. X-Area Integrate; 1.71.0.0; Stoe \& Cie GmbH: Darmstadt, Germany, 2016.

31. X-Area X-Red; 1.63.2.0; Stoe \& Cie GmbH: Darmstadt, Germany, 2017.

32. Palatinus, L.; Chapuis, G. SUPERFLIP- a computer program for the solution of crystal structures by charge flipping in arbitrary dimensions. J. Appl. Crystallogr. 2007, 40, 786-790. [CrossRef]

33. Petříček, V.; Dušek, M.; Palatinus, L. Crystallographic Computing System JANA2006: General features. Z. Kristallogr. 2014, 229, 345-352. [CrossRef]

34. SADABS; 2014/5; Bruker AXS Inc.: Madison, WI, USA, 2014.

35. XPREP; 2014/5; Bruker AXS Inc.: Madison, WI, USA, 2014.

36. Sheldrick, G.M. SHELXT-Integrated space-group and crystal-structure determination. Acta Crystallogr. A 2015, 71, 3-8. [CrossRef] [PubMed]

37. Sheldrick, G.M. Crystal structure refinement with SHELXL. Acta Crystallogr. Sect. C Cryst. Struct. Commun. 2015, 71, 3-8. [CrossRef] [PubMed]

(C) 2018 by the authors. Licensee MDPI, Basel, Switzerland. This article is an open access article distributed under the terms and conditions of the Creative Commons Attribution (CC BY) license (http:/ / creativecommons.org/licenses/by/4.0/). 